ARTICULO ORIGINAL

Rev Colombiana Cienc Anim 2016; 8(1):51-55.

POLIMORFISMOS NO GENE CAST EM OVINOS DO MATO GROSSO DO SUL, BRASIL

\author{
POLYMORPHISMS IN THE CAST GENE OF SHEEP FROM MATO GROSSO DO \\ SUL, BRAZIL
}

\title{
POLIMORFISMOS EN EL GEN CAST EN OVINOS DEL MATO GROSSO DO SUL, BRASIL
}

\author{
SANTOS CG. JESSICA, ${ }^{1}$ Zootec, CRISPIM A. BRUNO,${ }^{2}$ M.Sc, SENO O. LEONARDO, ${ }^{1}$ Dr, VARGAS- \\ JUNIOR, M. FERNANDO, ${ }^{1}$ Dr, GRISOLIA B. ALEXÉIA,${ }^{3}$ Dra.
}

\begin{abstract}
${ }^{1}$ Universidade Federal da Grande Dourados (FCA-UFGD),Faculdade de Ciências Agrárias, Dourados, MS, Brasil. ¿Universidade Federal da Grande Dourados (FACET-UFGD), Faculdade de Ciências Exatas e Tecnologia, Dourados, MS , Brasil. ${ }^{3}$ Universidade Federal da Grande Dourados (FCBA-UFGD), Faculdade de Ciências Biológicas e Ambientais, Dourados, MS, Brasil.
\end{abstract}

Palavras chave:

Calpastatina, marcador molecular, maciez da carne, Ovis aries.

Key words:

Calpastatin, molecular marker, meat tenderness, Ovis aries.

INFORMACIÓN Recibido: 04-02-2016; Aceptado: 05-05-2016. Correspondencia autor: alexeiagrisolia@ufgd.edu.br

\section{Resumo}

O consumo de carne ovina tem aumentado nos últimos anos, necessitando assim do aumento de produção para suprir a demanda. No entanto, problemas associados à fatores de produção e a qualidade da carne fazem com que esta necessidade não seja atendida. A maciez da carne é uma das características organolépticas mais desejadas pelos consumidores e esta pode ser influenciada pela calpastatina, proteína sintetizada por um gene candidato calpastatina (CAST) localizado no exon 29 do cromossomo cinco em ovinos que inibe a atividade proteolítica da $\mu$-calpaína e regula o amaciamento da carne no post mortem. Neste contexto, o objetivo deste estudo foi determinar as frequências alélicas e genotípicas de polimorfismos do gene CAST em ovinos da raça Pantaneira, lle de France, Suffolk e Bergamácia Brasileira. A caracterização alélica e genotípica foi realizada em 50 animais de cada raça, utilizando a PCR-RFLP. Os produtos amplificados e digeridos foram submetidos à eletroforese em gel de agarose $2 \%$ corados com brometo de etídio. Nas raças investigadas foram observados dois alelos ( $\mathrm{M}$ e N) e três genótipos (MM, MN e NN) para o gene CAST. O alelo M foi o mais frequente (72\%) quando todos os indivíduos foram considerados. As frequências genotípicas MM, MN e NN por raça foram de 58, 23 e 19\% na Pantaneira, de 28, 34 e 38\% na Bergamácia, de 80, 16 e 4\% na Suffolk e de 82, 12 e 6\% na lle de France. Considerando que polimorfismos nesse gene estejam associados à maciez da carne, a variação nas frequências genotípicas e alélicas diagnosticada indica perspectivas futuras para estudos de associação.

\footnotetext{
Abstract

The consumption of sheep meet has increased in recent years, thus necessitating increased production to meet demand. However, problems associated with production and meat quality make this need not met. The tenderness of the meat is one of the organoleptic characteristics most desired by consumers and this can be influenced by calpastatin, protein synthesized by a candidate gene (CAST) located in the exon 29 of the five chromosome in sheep, which inhibits proteolytic activity of $\mu$-calpain and regulates the softening of meat in posmortem. In this context, the aim of this study was to determine the allelic and genotypic frequencies of polymorphisms of calpastatin gene (CAST) in sheep of Pantaneira breed, lle de France, Suffolk and Brazilian Bergamacia. Allelic and genotypic characterization was performed on 50 animals of each breed using PCR-RFLP. The amplified products were digested and subjected to electrophoresis in a $2 \%$ agarose gel and stained with ethidium bromide. In the investigated breeds were observed two alleles ( $\mathrm{M}$ and $\mathrm{N}$ ) and three genotypes (MM, MN and NN) for the CAST gene. The M allele was the most frequent $(72 \%)$ when all individuals were considered. The frequencies of genotype MM, MN and NN per class were 58, 23, and 19\% Pantaneira, 28, 34 and 38\% in Bergamacia, 80,16 and $4 \%$ Suffolk and 82,12 and $6 \%$ lle France. Whereas those polymorphisms in this gene are associated with meat tenderness, the variation in genotypic and allelic frequencies diagnosed indicates future prospects for associantion studies.
} 
Palabras Clave:

Calpastatina, marcadores moleculares, terneza de la carne, Ovis aries.

\section{Resumen}

En los últimos años es creciente el consumo de carne de ovino, lo que hace necesira una mayor producción para satisfacer esta demanda. Sin embargo, los problemas asociados con los factores de calidad de la carne y de producción hacen que esta necesidad no sea atendida. La terneza de la carne es una de las características organolépticas más deseadas por los consumidores y esta puede ser influenciada por la calpastatina, una proteína sintetizada por el gen candidato (CAST), situado en el exón 29 del cromosoma cinco en el genoma de ovinos, y que inhibe la actividad proteolítica de $\mu$-calpaína y regula el ablandamiento de la carne posmortem. En este contexto, el objetivo de este estudio fue determinar las frecuencias alélicas y genotípicas de los polimorfismos en el gen de la calpastatina (CAST) en ovinos de las razas Pantaneira, lle de France, Suffolk y Bergamasca brasileña. La caracterización genotípica y alélica se realizó en 50 animales de cada raza mediante PCR-RFLP. Los productos amplificados fueron digeridos y se sometieron a electroforesis en gel de agarosa $2 \%$ con bromuro de etidio. En las razas estudiadas se observaron dos alelos ( $\mathrm{M}$ y N) y tres genotipos (MM, NN y MN) para el gen CAST. Si se consideran todos los individuos, el alelo $\mathrm{M}$ fue el más frecuente $(72 \%)$. Las frecuencias de los genotipos $\mathrm{MM}, \mathrm{MN}$ y NN por raza fueron 58 , 23 , y $19 \%$ para Pantaneira, 28,34 y $38 \%$ en Bergamacia, 80,16 y $4 \%$ para Suffolk y por ultimo 82,12 y $6 \%$ lle Francia. Mientras que los polimorfismos en el gen CAST están asociados con la terneza de la carne, la variación de las frecuencias genotípicas y alélicas diagnosticados indican las nuevas perspectivas para estudio de asociación.

\section{Introdução}

No Brasil, a ovinocultura é uma atividade que apresenta perspectivas para aumento tanto produção como no consumo. Porém, para suprir a demanda é necessário que o setor seja mais eficiente e atenda as exigências quanto à qualidade da carne. (ESTEVES et al., 2010).

As condições climáticas, a disponibilidade de forrageiras e a grande área de pastagem tropical são aspectos que favorecem a expansão da ovinocultura pelo fato de proporcionarem tanto o abastecimento do mercado interno quanto o desenvolvimento da exportação da carne ovina (SIMPLíCIO et al., 2004). No centro-oeste brasileiro, o estado do Mato Grosso do Sul se destaca na produção de ovinos devido a aspectos relativos à localização geográfica e clima favorável (VARGAS JUNIOR et al., 2011).

No Brasil, a produção de ovinos em larga escala ainda é limitada apesar do seu alto potencial, devido principalmente a fatores ligados a cadeia produtiva que dificultam a produção de carcaças de qualidade, como: raça, ambiente, nutrição, variabilidade dos sistemas de criação e falta de padronização de carcaças produzidas (PÉREZ et al., 1998). Consequentemente, as exigências e critérios de qualidade estabelecidos pelos consumidores não são atendidas, tornando assim necessário o conhecimento de aspectos quantitativos e qualitativos relativos às características desejadas para melhorar a oferta do produto e atrair mais consumidores de carne ovina (BRESSAN et al., 2001).
A maciez da carne é uma das características organolépticas desejadas pelos consumidores, sendo relacionada tanto à fatores ante mortem ou intrínsecos (genética, idade, sexo, alimentação) como post mortem ou extrínsecos (estimulação elétrica, temperatura de esfriamento da carcaça e maturação, ou ainda ação de enzimas proteolíticas nas fibras musculares) que podem influenciar no rigor mortis e consequentemente na qualidade da carne (BELEW et al., 2003).

A calpaína e calpastatina são proteínas que constituem um complexo cálcio dependente e contribuem na proteólise post mortem (CARVALHO et al., 2007). Segundo PALMER et al., (1998) o gene da calpastatina (CAST) em ovinos está localizado no cromossomo 5 e possui $100 \mathrm{~kb}$. O gene é responsável por inibir a atividade da calpaína impedindo a sua atuação na degradação miofibrilar post mortem, diminuindo a maciez da carne. Portanto, polimorfismos associados ao gene CAST podem influenciar a expressão gênica e afetar interação da calpaína/calpastatina consequentemente influenciando a qualidade da carne (BAGATOLI, 2011).

Devido à importância do gene CAST associado a aspectos que envolvem a qualidade da carne, o objetivo foi determinar as frequências alélicas e genotípicas em ovinos de diferentes raças sul mato-grossenses para o gene CAST por meio da técnica de PCR-RFLP. 


\section{Materiais e métodos}

O grupo amostral composto por 200 animais distribuídos nas raças: Pantaneira (50), Suffolk (50), lle de France (50) e Bergamácia Brasileira (50) provenientes de rebanhos da região do Mato Grosso do Sul. Amostras de sangue foram coletadas por punção da veia jugular em tubos à vácuo $(4,5 \mathrm{~mL})$ com EDTA e estas foram refrigeradas $\mathrm{a}-20^{\circ} \mathrm{C}$ até $\mathrm{o}$ momento de extração do DNA.

A extração de DNA foi realizada segundo o protocolo proposto por CRISPIM et al. (2012). A quantificação do material genético foi realizada em espectrofotômetro (Nanophometer Implen 300) para avaliar a concentração e pureza do DNA. A concentração média de DNA foi de $50 \mathrm{ng} / \mu \mathrm{L}$ e a razão de 1,6 a 1,8 (260/280nm de absorbância). A integridade do DNA também foi avaliada em eletroforese em gel de agarose $2 \%$.

O gene CAST foi amplificado por meio da PCR (Polimerase Chain Reaction), utilizando os primers CAST Forward: 5'-TGG GGC CCAATG ACG CCA TCG ATG-3' e CAST Reverse: 5'-GGT GGA GCA GCA CTT CTG ATC ACC -3' (Número de acesso no GenBank: L14450), produzindo um fragmento de $622 \mathrm{pb}$ (PALMER et al., 1998). A PCR foi realizada em termociclador (BIORAD) e constituiu de desnaturação inicial de $95^{\circ} \mathrm{C}$ (3 min), seguido por 35 ciclos de desnaturação a $95^{\circ} \mathrm{C}$ (1 min), anelamento a $59^{\circ} \mathrm{C}(1 \mathrm{~min})$, extensão a $72^{\circ} \mathrm{C}(2$ min) e extensão final a $72^{\circ} \mathrm{C}(7 \mathrm{~min})$. Posteriormente à amplificação as amostras foram visualizadas em gel de agarose a $2 \%$ corado com brometo de etídio.

Os produtos de PCR foram digeridos pela enzima Mspl (Moraxella species) a $37^{\circ} \mathrm{C}$ por 4 horas. A discriminação dos genótipos realizada a partir desta enzima com sitio de restrição ( $\left.C^{\wedge} C G G\right)$ foi responsável pela digestão do alelo $\mathrm{M}$, mas não o alelo $\mathrm{N}$. Os produtos da digestão foram separados por meio de eletroforese (120 v/150 $\mathrm{mA}$ ) durante 35 minutos em gel de agarose $2 \%$ corado com brometo de etídio.
As frequências alélicas e genotípicas, heterozigosidade observada $(\mathrm{HO})$ e esperada (HE), equilíbrio de HardyWeinberg (HW) e o Conteúdo de Informação Polimórfica (PIC) foram calculados pelo software CERVUS 3.0 (KALINOWSKI et al., 2007).

\section{Resultados}

A amplificação a partir do DNA resultou em um fragmento de 622 pb. Após a digestão com a enzima de restrição $\mathrm{Mspl}$, foram observados três genótipos diferentes. O genótipo MM apresentou duas bandas de 336 e 286 pb, o MN três bandas de 622, 336 e 286 pb e o NN apenas uma banda de 622 pb (Fig. 1).

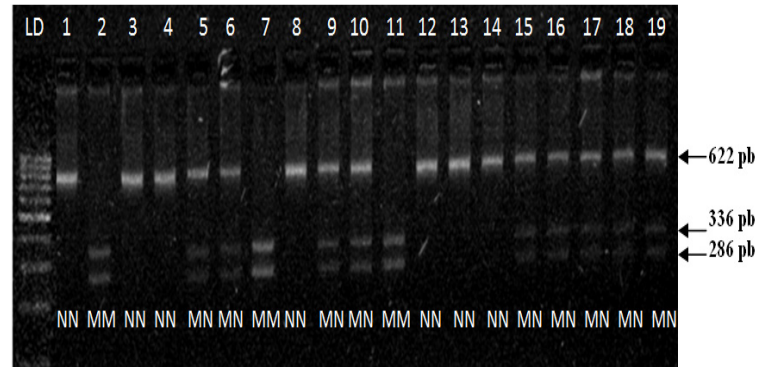

Figura 1. Eletroforese em gel de agarose $2 \%$. Produtos da digestão do gene CAST, genótipos MM (336 e 286 pb), colunas: 2, 7, e 11; MN (622 pb, 336 pb e 286 pb), colunas: $5,6,9,10,15,16,17,18$, e 19 e NN (622 pb), colunas: $1,3,4,8,12,13$ e 14 ; LD (100 pb).

Em todas as populações foram encontrados os três genótipos (MM, MN e NN). As raças Suffolk (origem inglesa com aptidão para carne) e lle de France (origem francesa com aptidão para carne e lã) apresentaram os maiores valores de frequências alélicas para o alelo $\mathrm{M}(88 \%)$, seguida da raça Pantaneira (70 \%). No entanto, o alelo $\mathrm{N}$ foi mais frequente na Bergamácia Brasileira (originada da raça Bergamasca do Sudão com aptidão para carne, leite e lã) (55\%). As frequências alélicas e genotípicas, heterozigosidade observada e esperada, equilíbrio de Hardy-Weinberg e o Conteúdo de Informação Polimórfica estão descritos na Tabela 1.

Tabela 1. Resultados das frequências genotípicas e alélicas, Ho, He, PIC, HW para o gene da CAST.

\begin{tabular}{|c|c|c|c|c|c|c|c|c|c|c|}
\hline \multirow{2}{*}{ Raças } & \multirow{2}{*}{$\mathbf{N}$} & \multicolumn{3}{|c|}{ Frequência genotípica } & \multicolumn{2}{|c|}{ Frequência alélica } & \multirow{2}{*}{ Ho } & \multirow{2}{*}{$\mathrm{He}$} & \multirow{2}{*}{ PIC } & \multirow{2}{*}{ HW } \\
\hline & & MM & MN & NN & M & $\mathbf{N}$ & & & & \\
\hline Pantaneira & 50 & 0,58 & 0,23 & 0,19 & 0,70 & 0,30 & 0,23 & 0,42 & 0,33 & $0,003^{*}$ \\
\hline Bergamácia & 50 & 0,28 & 0,34 & 0,38 & 0,45 & 0,55 & 0,34 & 0,50 & 0,37 & $0,04^{*}$ \\
\hline Suffolk & 50 & 0,80 & 0,16 & 0,04 & 0,88 & 0,12 & 0,16 & 0,21 & 0,19 & $0,2^{\mathrm{NS}}$ \\
\hline Ile de France & 50 & 0,82 & 0,12 & 0,06 & 0,88 & 0,12 & 0,12 & 0,21 & 0,19 & $0,009^{*}$ \\
\hline
\end{tabular}

$\mathrm{N}=$ Número de indivíduos; $\mathrm{Ho}=$ Heterozigosidade observada; $\mathrm{He}=$ Heterozigosidade esperada; $\mathrm{PIC}=$ Conteúdo de informação polimórfica; HW= equilibrio de Hardy-Weinberg. ${ }^{*} p>0,05 ;{ }^{* \star} p>0,01$ 


\section{Discussão}

A raça Bergamácia apresentou maior porcentagem de alelos $\mathrm{N}$, o que pode ser considerado indicativo de que esse alelo esteja relacionado à especificidade desta raça para a produção de carne e leite, habilidade materna e prolificidade (SANTOS, 1986). A presença do alelo $\mathrm{N}$ pode estar associada à produção de carne com menor maciez. Estudos realizados com bovinos da raça Angus, obteve frequência de 0,75 para o alelo $M$, porém não foram observados resultados significativos para força de cisalhamento relacionados à presença dos alelos (M e N) (CHUNG et al., 2001).

A raça Pantaneira (naturalizada no Brasil com características de carcaça e boa qualidade da carne) apresentou-se intermediária, obtendo frequência alélica de $70 \%$ para o alelo $\mathrm{M}$ e de $30 \%$ para o $\mathrm{N}$. Este fato pode ser explicado por se tratar de uma raça localmente adaptada e apresentar miscigenação com outras populações analisadas, podendo assim ser considerada uma raça base das demais (CRISPIM et al., 2013; CRISPIM et al., 2014).

Em estudos com ovinos Corriedale (origem neozelandesa com aptidão para lã e carne) foi identificada frequência de $77 \%$ para o alelo M e $23 \%$ para o alelo N (PALMER et al., 1998) e em ovinos Zel (origem iraniana com aptidão para lã e carne) as frequências alélicas foram de $85 \%$ para o alelo $\mathrm{M}$ e de $15 \%$ para o alelo N (DEHNAVI et al., 2012).

A heterozigosidade observada $(\mathrm{Ho})$ e esperada $(\mathrm{He})$ foi de 0,23 e 0,42 para a raça Pantaneira, de 0,34 e 0,50 para a Bergamácia, 0,16 e 0,21 para a Suffolk e de 0,12 e 0,21 para lle de France. Portanto, observa-se que em todas as raças a $\mathrm{He}$ foi superior a $\mathrm{Ho}$, sendo indicativo de endogamia nas populações estudadas e diminuição da diversidade genética destes animais (EGITO, 2007). Analisando o Conteúdo de Informação Polimórfica (PIC) referente ao marcador observouse que todos os resultados podem ser considerados como pouco informativos, pois todos os valores foram inferiores a 0,7 (BOTSTEIN et al., 1980).

Quanto aos resultados do equilíbrio de Hardy-Weinberg (HW) notou-se que somente a raça Suffolk estava em equilíbrio, indicado pelo desvio significativo e que a maior parte da população estudada era endogâmica, ou seja, provenientes de cruzamentos entre indivíduos mais aparentados entre si na população (MENEZES, 2005).

Foi possível notar que o marcador CAST/Msp/ permitiu a caracterização genotípica e fenotípica das populações de ovinos em estudo, sendo o alelo M o mais frequente, o que indica que este alelo pode estar associado à maciez da carne em ovinos, uma vez que sua incidência foi maior em três das quatro raças estudadas. Perspectivas futuras de estudos de polimorfismos nesse gene associado à características fenotípicas de maciez de carne em rebanhos de diferentes raças (diferentes origens) poderão auxiliar na seleção de animais para a característica de maciez.

Agradecimentos: À Universidade Federal da Grande Dourados (UFGD), ao Conselho Nacional de Desenvolvimento Científico e Tecnológico (CNPq) e a Fundação de Apoio ao Desenvolvimento do Ensino, Ciência e Tecnologia do Estado de Mato Grosso do Sul (FUNDECT) pelos recursos financeiros e apoio logístico.

\section{Referências}

BAGATOLI, A. 2011. Expressão gênica da calpastatina e miostatina associada com o desempenho e qualidade de carne em ovinos. Dissertação (Mestrado em Zootecnia) - Universidade Estadual de Maringá, Área de Concentração em Produção Animal. Maringá, PR.

BELEW, J.B.; BROOKS, J.C.; MCKENNA, D.R.; SAVELL, J.W. 2003. Warner-Bratzler Shear evaluations of 40 bovine muscles. Meat Science 64 (4):507-512.

BOTSTEIN, D.; WHITE, R.L.; SKOLNICK, M.; DAVIS, R.W. 1980. Construction of a genetic map in man using restriction fragment length polymorphism. The American Journal of Human Genetics 32:314-331.

BRESSAN, C.; PRADO, O.V.; PÉREZ, J.R.O. 2001. Efeito do peso ao abate de cordeiros Santa Inês e Bergamácia sobre as características físico-químicas da carne. Food Science Technology 21 (3):293-303.

CARVALHO, M.E.; ELER, J.P.; AFAZ, A.L.M.; FERRAZ, J.B.S.; REGITANO, L.C.A.; MEIRELLES, F.V.; BALIEIRO, J. C. C. A. 2007. Avaliação de diferentes combinações genotípicas para polimorfismo no gene u-calpaína e calpastatina associados com a maciez da carne em animais da raça Nelore. In: Congresso brasileiro de ciência e tecnologia de carnes. Mercado do Século XXI: qualidade, segurança alimentar, certificação e rastreabilidade - anais. Campinas, SP: ITAL/CTC. 
CHUNG, H.Y.; DAVIS, M.E.; HINES, H.C. 2001. Relationship pf two PCR-RFLP in the bovine calpastatin gene with calpastatin activity, meat tenderness and carcass traits. International Society for Animal Genetics 32:40-53.

CRISPIM, B.A.; GRISOLIA, A.B.;SENO, L.O.; EGITO, A.A.; VARGAS JUNIOR, F.M.; SOUZA, M.R. 2013. Genetic diversity of locally adapted sheep from Pantanal region of Mato Grosso do Sul. Genetics and Molecular Research 12:5458-5466.

CRISPIM, B.A.; SENO, L.O.; EGITO, A.A.; VARGAS JUNIOR, F.M.; GRISOLIA, A.B. 2014. Application of microsatellite markers for breeding and genetic conservation of herds of Pantaneiro sheep. Electronic Journal of Biotechnology 17 (6):317-321.

CRISPIM, B.A.; SILVA, D.B.S.; BANARI, A.C.; SENO, L.O.; GRISOLIA, A.B. 2012. Discriminação Alélica em Ovinos Naturalizados do Pantanal Sul-Matogrossense por Meio de Marcadores de Microssatélites. Journal of Selva Andina Research Society 3:3-13.

DEHNAVI, E.; AZARI, M.A.; HASANI, S.; NASSIRY, M.R.; MOHAJER, M.; AHMADI, A.R.K. 2012. Genetic variability of calpastatin and calpain genes in Iranian Zel sheep using PCR-RFLP and PCR-SSCP methods. Iranian Journal of Biotechnology 1 (10):136-139.

EGITO, A.A. 2007. Diversidade genética, ancestralidade individual e Miscigenação nas raças bovinas no Brasil com base em Microssatélites e haplótipos de DNA mitocondrial: Subsídios para a conservação. Tese (Doutorado em Ciências Biológicas) - Universidade de Brasília, Brasília.

ESTEVES, R. M. G.; OSÓRIO, J. C. S.; OSORIO, M. T. M.; MENDONÇA, G.; OLIVEIRA, M. M.; WIEGAND, M.; VILANOVA, M. S.; CORREA, F.; JARDIM, R. D. 2010. Avaliação in vivo e da carcaça e fatores determinantes para o entendimento da cadeia da carne ovina. Revista Brasileira de Agrocicências, Pelotas 16 (1/4):101-108.

KALINOWSKI, S.T.; TAPER, M.L.; MARSHALL, T.C. 2007. Revising how the computer program CERVUS accommodates genotyping error increases success in paternity assignment. Molecular Ecology 16:1099-1106.

MENEZES, M.P.C. 2005. Variabilidade e relações genéticas entre raças caprinas nativas brasileiras, ibéricas e canárias. Tese (Doutorado em Produção Animal) - Universidade Federal da Paraíba. Universidade Federal Rural de Pernambuco, Universidade Federal do Ceará, Areia.

PALMER, B.R.; ROBERTS, N.; HICKFORD, J.G.; BICKERSTAFFE, R. 1998. Rapid communication: PCR-RFLP for $\mathrm{Mspl}$ and $\mathrm{Ncol}$ in the ovine calpastatin gene. Journal of Animal Science 67:1499-1500.

PÉREZ, J.R.O.; GARCIA, I.F.F.; TEIXEIRA, J.C. 1998. Características de carcaça de cordeiros Santa Inês e Bergamácia com diferentes níveis de dejetos de suínos na dieta. In: Reunião anual da sociedade brasileira de zootecnia, Anais . Botucatu: SBZ 35:176-178.

SANTOS, V.T. 1986. Ovinocultura. Princípios básicos para sua instalação exploração. Nobel. São Paulo, Brasil.

SIMPLÍCIO, A.A.; WANDER, A.E.; LEITE, E.R.; LOPES, E.A.A. 2004. Caprino-ovinocultura de Corte como Alternativa para a Geração de Emprego e Renda. Sobral: Embrapa Caprinos. Brasil.

VARGAS JUNIOR, F.M.; MARTINS, C.F.; SOUZA, C.C.; PINTO, G.S.; PEREIRA, H.F.; CAMILO, F.R.; F. R.; JUNIOR, N. P. A. 2011. Avaliação biométrica de cordeiros pantaneiros. Revista Agrarian 4:60-65. 